Nig. J. Biotech. Vol. 32 (2017) 28 - 32

ISSN: 01891731

Available online at

http://www.ajol.info/index.php/njb/index

and www.biotechsocietynigeria.org

DOI: http://dx.doi.org/10.4314/njb.v32i1.5

\title{
Bone Morphogenetic Protein 3 (BMP3) Gene Variation in some Livestock Animals
}

\author{
Agaviezor, B. O., Ajayi, F. O. and Omoyibo, T. W. \\ Department of Animal Science, University of Port Harcourt, Port Harcourt, Nigeria.
}

\begin{abstract}
Variation in Bone Morphogenetic Protein 3 (BMP3) genes in some selected livestock animals was assessed using sequences downloaded from the GenBank (https://www.ncbi.nlm.nih.gov/genbank/). The analysis was carried out in 36 pair-wise comparisons where averages of 1277.780 sites were analyzed. Analysis at individual sites revealed a nucleotide diversity $(\mathrm{Pi})$ of 0.566 . Theta-W per sequence was 611.817 while Theta-W per site was 0.387 . Gene flow estimates using haplotype data information showed Gst value as 0.013 while gene flow estimates using sequence data information revealed, Delta St of $\mathbf{0 . 1 3 1}$, and Gamma St of 0.270. Furthermore, Nst value was $\mathbf{0 . 0 0 6 1 8}$ and Fst, -0.019 . The highest genetic distance at the Bone Morphogenetic Protein 3 (BMP3) gene loci between the organisms under this study was that between chicken and sheep (85.00) and the lowest distance were seen between cattle and sheep (9.66). The dendogram revealed two major clusters. Chicken and goats were closely related at the Bone Morphogenetic Protein 3 (BMP3) gene locus and both were separated from the other cluster which comprises of cattle, sheep, and rabbit. This study has revealed vital information that will help in better understanding the relatedness in the functions of the bone morphogenetic protein 3 genes in these selected livestock animals.
\end{abstract}

Keywords: Bone Morphogenetic Protein 3, gene, livestock

Correspondence: brilliant.agaviezor@uniport.edu.ng

\section{Introduction}

The rapidly growing population of man means an increased demand for food, livestock product inclusive, to meet the nutritional needs of man and this has led to indiscriminate breeding of farm animals in a bid to improve productivity (Adebambo et al., 2011). The importance of livestock breeds in meeting the protein need of Nigeria cannot be over emphasized. To this end, livestock improvement has become one of the means of increasing meat and milk production and this can be achieved by a better understanding of the genetic make-up of these animals. Specific genes have been studied to understand their functions as well as the level of their polymorphism within and across breeds and species.

A genetic polymorphism study in domestic animals is aimed at evaluating genetic variation within and across breeds mainly for improvement and conservation purposes (Saleha, 2012). Bone morphogenetic proteins (BMPs) are seen in ovarian growth factors and play a central role in determining ovulation quota and litter size. Also, the understanding of the role of BMPs in reproduction assists in treatment of infertility and sterility in animals. Bone Morphogenetic proteins (BMPs) are multifunctional growth factors $\beta$ (TGF $\beta$ ) super family. They play major role in embryonic development and cellular functions in postnatal and adult animals (Chen et al., 2004).

Also, BMPs induce formation of both cartilages and bones, and non-osteogenic developmental process (Chen et al., 2004). The main objective of this study was to assess the variation in the Bone Morphogenetic Morphogenetic Protein 3 (BMP3) gene which is linked with bone formation in some selected livestock breeds to have more information 
needed for their improvement and conservation.

\section{Materials and Methods}

Both partial and complete sequences of Bone Morphogenetic Protein 3 (BMP3) genes for sheep, chicken, rabbits, goats and cattle were retrieved from the Genbank (https://www.ncbi.nlm.nih.gov/genbank/). These sequences were aligned and edited to uniform length of bases using MEGA 4.0. Tools for Population Genetic Analyses (TFPGA) version 1.3 (Miller, 1997) and Mega 4.0 were then used to determine nucleotide diversity, number of polymorphic sites, average number of sites analyzed, average number of differences among the sequences analyzed as well as gene flow estimates. The analysis was carried out in 36 pair-wise comparisons where an average of 1277.780 sites was analyzed.

\section{Results}

From Table 1, the result of analysis in pair wise comparison showed an average number of nucleotide differences of 691.639 and a nucleotide diversity (Pi) of 0.539 . Analysis at individual sites revealed 1580 analysed sites and 1491 number of polymorphic sites. Average number of nucleotide differences was 895.839 and nucleotide diversity was 0.566 . Theta-W per sequence was 611.817 and Theta-W per site was 0.387. Gene flow estimates using haplotype data information showed Gst value as 0.013 whereas $\mathrm{Nm}$ was 18.00 .

Table 1: Variation in sequences of Bone Morphogenetic Protein 3 in selected livestock species

\begin{tabular}{lc}
\hline Analysis in pair wise comparisons & Values \\
\hline Number of pair wise comparisons: & 36.000 \\
Average number of sites analyzed: & 1277.780 \\
Average number of differences: & 691.639 \\
Nucleotide diversity, Pi: & 0.539 \\
Analyses at individual sites (column by column) & \\
Number of sites analyzed: & 1580.000 \\
Number of polymorphic sites, S: & 1491.000 \\
Average number of differences: & 895.839 \\
Nucleotide diversity, Pi: & 0.566 \\
Theta-W per sequence: & 611.817 \\
Thete-W per site: & 0.387
\end{tabular}

Gene flow estimates using sequence data information, revealed Delta St as 0.131 , Gamma St was 0.270 and $\mathrm{Nm}$ as 0.67 . Also,
Nst was 0.006 with a $\mathrm{Nm}$ of 40.20 . However, Fst was -0.019 with an $\mathrm{Nm}$ of -13025 as shown in Table 2.

Table 2: Gene flow estimates

\section{Haplotype Data information}

Gst: $0.01370 \quad \mathrm{Nm:} 18.00$

\section{Sequence Data Information}

Delta St: 0.13107

Gamma St: $0.27053 \quad \mathrm{Nm}: 0.67$

Nst: 0.00618

$\mathrm{Nm}: 40.20$

Fst: -0.01923

$\mathrm{Nm}:-13025$

As indicated in the Table 3, the genetic distance between rabbit and chicken at the bone marrow gene locus is 83.222 , between rabbit and goat is 74.086 , between rabbit and cattle is 14.460 , between rabbit and sheep is
18.685. The genetic distance between goat and chicken is 19.622, between goat and cattle is 76.966 and between goat and sheep is 81.845 . 
Table 3. Pair wise genetic distance between these organisms at the bone marrow gene 3 locus

\begin{tabular}{llllll}
\hline & Chicken & Rabbit & Goat & Cattle & Sheep \\
\hline Chicken & 0 & & & & \\
Rabbit & 83.222 & 0 & & & \\
Goat & 19.622 & 74.086 & 0 & & \\
Cattle & 21.826 & 14.460 & 76.966 & 0 & \\
Sheep & 85.003 & 18.685 & 81.845 & 9.660 & 0 \\
\hline
\end{tabular}

The genetic distance between cattle and chicken is 21.826 and between cattle and sheep is 9.660 . The dendogram below shows the cluster of the various species analyzed at the bone marrow gene 3 (Figure 1).

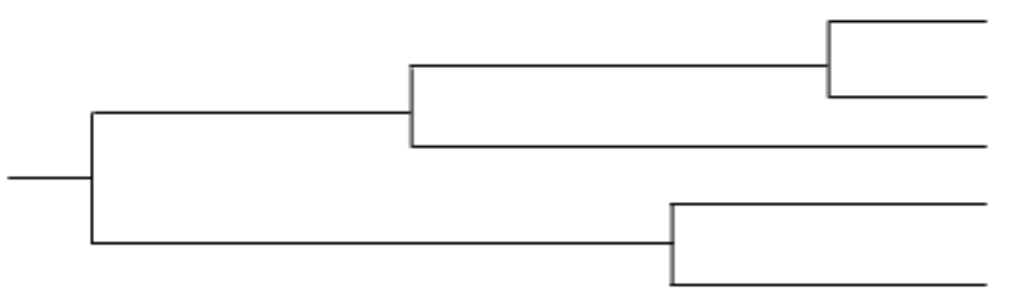

\section{Cattle \\ Sheep \\ Rabbit \\ Chicken \\ Goat}

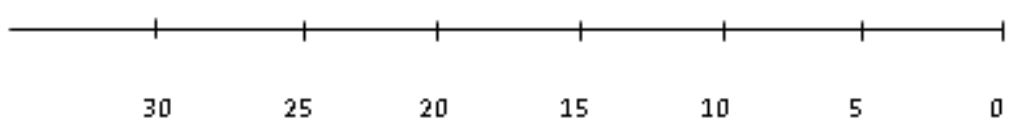

Figure 1: Dendogram showing clusters of different species at the bone marrow locus.

The dendogram revealed two major clusters. Chicken and goats were closely related at the Bone Morphogenetic Protein 3 (BMP3) gene and both were separated from the other cluster that comprises cattle, sheep and rabbit.

\section{Discussion}

The average value of nucleotide diversity observed in this study is expected since the sequences of this gene under study were compared across species. This is confirmed by the number of differences in the sequences both when compared pair wise as well as at individual sites (column by column). Theta - $W$ per sequence and site explained the difference between the mean number of pairwise differences and the number of segregating sites, each scaled so that they are expected to be the same in a neutrally evolving population of constant size (Tajima, 1989). Furthermore, the high level of polymorphic sites reported in this study as an indication of the level of diversity in this gene under study across the organisms considered.

A significant gene flow estimates were observed both from the haplotype and sequence data information. Gst which is an estimate that measures genetic differentiation is inversely proportional to gene flow. The low Gst values therefore recorded is explained by the level of polymorphism. $F_{S T}$ was originally formulated to measure genetic distance using biallelic markers (Wright, 1969), but was generalized for multiple alleles (Nei, 1973), referred to as $G_{S T}$ (although confusingly, the terms $G_{S T}$ and $F_{S T}$ are often used interchangeably. However, Hedrick (2005) and Meirmans and Hedrick (2011) have pointed 
out a difficulty in interpreting $G_{S T}$. With two populations and two alleles, $G_{S T}$ ranges from 0.0 to 1.0 , as expected, with 0 representing no differences in allele frequencies between two populations and 1.0 indicating that the two populations are fixed for alternate alleles. The values for nucleotide diversity varies significantly from $0.106,0.022$ and 0.016 observed by Anila et. al. (2014) for Capore, Dukati and Hasi goat breeds respectively. This also was higher than those reported of Lieshy et al. (2013), who reported $0.01152,0.01131$ and 0.1225 for three breeds of Tanzanian goats. $G_{S T}$ which is also called Nei's coefficient of differentiation, equivalent to Fst of Wright was generally low. This may indicate that Bone Mophogenetic Protein 3 gene is not differentiated enough across these species.

The Fst values observed in this research is low. This implies that the measure of the difference in the allele frequency of this gene between the populations is low. Similar value was reported by Anila et al. (2014) for Capore breed of goat but different from -5.589 and -5.469 reported by Anila et al. (2014) for Dukati and Hasi breeds of goats. Gene flow means the movement of genes. In some cases, small fragments of DNA may pass from one individual directly into the germline of another, perhaps transduced by a pathogenic virus or other vector, or deliberately via a human transgenic manipulation (Mallet, 2001). If individuals of a species are clustered into distinct populations, gene flow between populations can be described as the product of the effective population size $(\mathrm{N})$ and the proportion of migrants per generation $(\mathrm{m})$. If populations are of similar size, then $\mathrm{Nm}$

\section{References}

Adebambo, A. O., Adebambo, O., Williams, J. L., Blott, S. and Urquart, B. (2011). Genetic distance between two popular Nigerian goat breeds used for milk production. Livestock Research for Rural Development. Volume 23, Article \#26. Retrieved March 18, 2016, from http://www.Irrd.org//rrd23/2/adeb23026.htm

Anila, H., Yili, B. and Petrit, D. (2014). Genetic diversity of Albanian goat by mtDNA sequence variation ISSN: $1310-2818$ (print) $1314-3530$

Anita, Y. and Yadar, B.R. (2007). Genetic diversity among 6 breeds of goats in India describes the average number of individuals per generation migrating between populations (Wolf and Soltis, 1991).

The values recorded for $\mathrm{Nm}$ under the haplotype and sequence data information explains the level of gene flow across the livestock animals considered in this study. The significance of $\mathrm{Nm}$ was first considered for an island model by Wright (1969), who determined theoretically that if more than one individual migrates between populations every other generation $(\mathrm{Nm}>0.5)$, different alleles at a locus in the two populations would not become fixed due to genetic drift. Thus, gene flow is the major determinant of population structure when $\mathrm{Nm}>0.5$ and significant genetic differentiation can result from genetic drift when $\mathrm{Nm}<0.5$ (Wolf and Soltis, 1991). $\mathrm{F}_{\mathrm{ST}}$ is the reduction in heterozygosity due to population structure or (for biallelic markers) the variance in allele frequencies among populations. The value of Fst recorded in this study shows a higher reduction in heterozygosity.

\section{Conclusion}

This study has been able to reveal the variation in Bone Morphogenetic Protein 3 (BMP3) genes in the livestock breeds studied. Also, the highest genetic distance was between sheep and chicken while the lowest genetic distance was between cattle and sheep. The information gathered from this study will help in better understanding the variability in the sequences Bone Morphogenetic Protein 3 (BMP3) genes among the species studied.

using RADP markers. Biotechn. 6(1):57-60, ISSN 1682-296x.

Chen, D., Zhao, M. and Mundy, G. R. (2004). Bone Morphogenetic Protein. PubMEd 22 (4): 233-41

Hedrick PW (2005). A standardized genetic differentiation measure. Evolution, 59, 16331638.

Karima, F.M., Seleha, Y.M., Atakilli, Limna M.S., Sekena, H.A. and El-hanafy A.A. (2013). 
Genetic diversity in Egyptian and Saudi goat breeds using microsatellite markers. J. App. Bioscience 72:5838-5845. ISSN 1997-5902

Liesly, C.P. (2013). Mountain goat genetic diversity and population connectivity in Washington and southern British Colombia. An MSc Thesis presented to the Faculty of Western Washington University, USA. pp 112.

Mallet, J. (2001). Gene Flow, Calton Laboratory, Department of Biology, University College London, 4 Stephenson Way, London NWI 2HE, UK $337-360$

Meirmans, P.G. and Hedrick, P.W. (2011). Assessing population structure: $F_{S T}$ and related measures. Mol. Ecol. Res. 11: 5-18.

Miller, M.P. (1997). TFPGA-tools for population genetics analyses, version 1.3. A windows programme for the analysis of allozyme and molecular population genetic data. Department of Biological Sciences, Northern Arizona University, Flagstaff, 53 pp.

Nei, M. (1973). Analysis of gene diversity in subdivided populations. Pro. Nat. Acad. Sci. 70: 3321-3323.

Paul, G. W. and Pamela, S. S. (1991).

Estimates of Gene Flow among Populations, Geographic Races, and Species in the Ipomopsis aggregata Complex, Department of Botany, Washington State University, Pullman, Washington 99164-4238.

Seleha, Y.M., Karima, F.M., Lamiaa, M.S. and Ekram, S.A. (2012). Genetic polymorphism of five genes associated with goat traits in goats. Afr. J. Biotech. 11 (82) : 14738-14748

Tajima, F. (1989). Statistical method for testing the neutral mutation hypothesis by DNA polymorphism. Genetics. 123 (3): 58595.

Wright, S. (1969). Evolution and the Genetics of Populations, Vol. 2. University of Chicago Press, Chicago. Pp 1-3. 